\title{
Cost evaluation of PAGE-B risk score guided HCC surveillance in patients with treated chronic hepatitis $B$
}

\author{
Martin F. Sprinzl ${ }^{1,2^{*}}$ D, Christina Feist ${ }^{1}$, Sandra Koch ${ }^{1}$, Wolfgang M. Kremer ${ }^{1}$, Karl J. Lackner ${ }^{2}$, Arndt Weinmann ${ }^{1}$ and
} Peter R. Galle ${ }^{1}$

\begin{abstract}
Background: The PAGE-B score (Platelet Age GEnder-HBV) selects chronic hepatitis B (cHB) patients showing no relevant 5-year risk for hepatocellular carcinoma (HCC). We, therefore, explored potential cost reduction following the introduction of a PAGE-B tailored ultrasound screening in a single center cohort of cHB patients receiving stable antiviral therapy.

Methods: $\mathrm{CHB}$ patients attending throughout the year 2018 were documented. Patients eligible for PAGE-B score were classified into high ( $\geq 18$ points), intermediate (10-17 points) and low ( $\leq 9$ points) HCC risk groups. Patients of the low HCC risk group could postpone HCC screening to reduce HCC screening expenses. Full costs for hepatic ultrasound were assessed.

Results: Throughout the year CHB patients $(n=607)$ attended our clinic, which included PAGE-B eligible patients ( $n=227,37.4 \%)$ of whom $n=94$ (15.8\%) were allocated to the low HCC risk group. Sonographic HCC screening during a median exam time of $12.4 \mathrm{~min}$ (IQR 9.2-17.2) resulted in total costs of 22.82 Euro/exam. Additional opportunistic expenses caused by patient's lost earnings or productivity were 15.6-17.5 €/exam and 26.7 €/exam, respectively. Following a PAGE-B tailored HCC screening at our institution annual full costs for CHB patients could be reduced by $15.51 \%$, which equals a cost reduction by $1.91 \%$ for our total sonography unit. In comparison, 1.35\% up to $7.65 \%$ of HBV-infected patients of Caucasian descent could postpone HCC screening according to population-based estimates from Germany.
\end{abstract}

Conclusions: PAGE-B risk score adapted screening for HCC is an efficient and cost neutral tool to reduce costs for sonography in Caucasian patients with chronic hepatitis B receiving antiviral treatment.

Keywords: Hepatitis B, Hepatocellular carcinoma, PAGE-B, Score, Costs

\section{Background}

Patients suffering from chronic Hepatitis B (cHB) develop a relevant morbidity and mortality caused by hepatocellular carcinoma (HCC) [1]. Surveillance by

\footnotetext{
* Correspondence: martin.sprinzl@unimedizin-mainz.de

${ }^{1}$ Medical Department I, University Medical Center of the Johanne Gutenberg University Mainz, Langenbeckstrasse 1, 55131 Mainz, Germany

${ }^{2}$ Institute for Laboratory Medicine and Clinical Chemistry, University Medical Center of the Johanne Gutenberg University Mainz, Langenbeckstrasse 1, 55131 Mainz, Germany
}

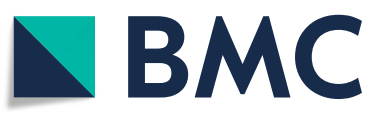

C C The Author(s). 2021 Open Access This article is licensed under a Creative Commons Attribution 4.0 International License, which permits use, sharing, adaptation, distribution and reproduction in any medium or format, as long as you give appropriate credit to the original author(s) and the source, provide a link to the Creative Commons licence, and indicate if changes were made. The images or other third party material in this article are included in the article's Creative Commons licence, unless indicated otherwise in a credit line to the material. If material is not included in the article's Creative Commons licence and your intended use is not permitted by statutory regulation or exceeds the permitted use, you will need to obtain permission directly from the copyright holder. To view a copy of this licence, visit http://creativecommons.org/licenses/by/4.0/ The Creative Commons Public Domain Dedication waiver (http://creativecommons.org/publicdomain/zero/1.0/) applies to the data made available in this article, unless otherwise stated in a credit line to the data.

ultrasonography has therefore been established in $\mathrm{cHB}$ patients and improves overall survival of cHB patients [2]. Therefore, cHB treatment guidelines recommend HCC surveillance in all patients with liver cirrhosis every 3 to 6 months. In $\mathrm{cHB}$ patients without liver cirrhosis a diagnostic screening is generally recommended annually $[3,4]$.

Additional risk stratification, however, has identified cHB patients with a considerably lower cumulative 
HCC-incidence, who might not require HCC surveillance. Particularly antiviral therapy with nucleos(t)ide analogues (NA) has reduced the HCC risk of $\mathrm{cHB}[5$, 6], which remains only minimally higher compared to hepatitis B virus carriers without disease activity [7]. This uncertainty of residual HCC development in NA treated patients, was addressed by the PAGE-B risk score (Platelet Age GEnder-HBV) integrating age, gender and thrombocyte count, which selects primarily Caucasian patients with low HCC risk [8-10]. According to the PAGE-B score patients of the low HCC risk group ( $\leq 9$ points) do not develop HCC under stable NA therapy during a 5-year follow up [8]. The large body of evidence has led to the recommendation of the European Association for the Study of the Liver (EASL), that $\mathrm{cHB}$ patients categorized into the low PAGE-B risk group could postpone $\mathrm{HCC}$ surveillance [11].

Given this new clinical data, it became possible to optimize allocation of clinical resources for HCC surveillance in $\mathrm{CHB}$ patients. However, the cost reduction for HCC surveillance, following a PAGE-B guided screening has not been defined. Hence, we explored the proportion of PAGE-B eligible cHB patients and the corresponding sonography costs to characterize the economic potential of PAGE-B adapted HCC screening.

\section{Methods}

\section{Data acquisition and patient selection}

For this observational single center study patient data were retrospectively retrieved from the hospital information system. Chronic $\mathrm{cHB}$ patients attending the liver disease out-patient clinic throughout the year 2018 were identified by a positive serum HBs-antigen ( $\mathrm{HBsAg}$ ) and cHB complications such as liver cirrhosis and hepatocellular carcinoma (HCC) were documented. Patients coinfected with hepatitis $C$, hepatitis $\mathrm{D}$ and human immunodeficiency virus were excluded. The PAGE-B score was calculated based on age, gender and thrombocyte count. PAGE-B strata were classified into high ( $\geq 18$ points), intermediate (10-17 points) and low ( $\leq 9$ points) HCC risk groups (additional Table 1) [8]. Patients eligible for PAGE-B score assessment had to receive effective antiviral therapy with second generation NA including entecavir (ETV), tenofovir disoproxil fumarate (TDF) and tenofovir alafenamide fumarate (TAF) for at least 1 year. The trial was conducted according to the principles of the Declaration of Helsinki. Approval was provided by the local ethic committee (State Chamber of Medicine, Rhineland-Palatinate, Germany, ethics approval number: 2019-14,206) and by the data safety officer (University Medical Center, Mainz, Germany).

\section{Diagnostic ultrasonography and time acquisition}

HCC screening included an ultrasonography of the liver, spleen and adjacent lymph nodes. Each ultrasonography throughout April and May 2019 was monitored with an on-site time tracking device (Timeular cube) by the examiner himself. The time span for each ultrasound (total exam time) was analyzed. In parallel, the total turnaround time spent at the ultrasound unit was documented for each patient at the out-patient clinic front desk. A patient flow chart of the HCC screening is provided (additional Fig. 1).

A total of $n=268$ sonographies were assessed. Eventually, $n=147$ (54.9\%) exams allowed detailed time assessments, which included selective liver ultrasound in $n=$ 118 patients $(44.0 \%)$. The exams were frequently performed by a specialist of internal medicine, who provided eleven years of work experience. A smaller proportion of exams $(24.5 \%, n=36 / 147)$ were provided by an assistant doctor with 3 years of work experience.

\section{Diagnostic ultrasonography expenses}

The instrument expenses were 88,000 Euro $(€)$ based on an updated sonography unit (Hitachi Arietta V70) meeting modern standards for HCC screening. The yearly costs were calculated by linear depreciation over a period of 5 years as defined by the German tax legislation (http://geman-taxes.de/pdf/AfA.pdf). Expenses for instrument services were derived from the service contract $(3500 € / \mathrm{a})$. Facility expenses, including room rent, energy supply, water supply and cleaning services, were covered by the institutional allowance over $140.91 €$ per squaremeter per year. Consumable costs were based on listed prices as provided by the institutional purchase department. Work place software licenses for administration (i.s.h.med ${ }^{\circ}$, SAP), picture archiving and communication (ViewPoint ${ }^{\circ}$, GE healthcare IT) were included.

Average personnel costs were derived from the staff roster of the past 2 years. The team involved in HCC screening included one medical doctor performing the exam, one nurse providing medical assistance and two healthcare assistants providing administration. Labour costs were based on the collective bargaining agreement for public service employees (38.5 working hours/ week) amended at the 11.02.2015 (E\&E-TV UM). Wage labour costs for medical staff (42 working hours/ week) were based on the collective bargaining agreement amended at the 01.01.2015 (TV-Ärzte/Universitätsmedizin).

\section{Biostatistics}

Descriptive data are given in median and interquartile range (IQR) throughout the manuscript if not specified accordingly. 


\section{Results}

\section{Patient characteristics and PAGE-B score}

A cohort of $n=607$ patients with positive serum HBsAg were identified during the year 2018, who underwent laboratory work up and regular HCC screening during a total $n=1.210$ visits per year. Patients with confirmed cHB receiving second-generation NA for a minimum of 1 year $(n=227)$ were eligible for HCC risk assessment by the PAGE-B score. This led to the identification of patients of high $(n=33)$, intermediate $(n=100)$ and low $(n=94)$ HCC risk, respectively (Table 1$)$. Throughout the year, three patients of the total cHB cohort died, whereas no mortality was observed in the low HCC risk subpopulation. Mortality was caused by myocardial infarction $(n=1)$, terminal liver cirrhosis $(n=1)$ and hepatocellular carcinoma $(n=1)$. Patients with low HCC risk did also not develop any HCC during a median follow up of 21 months (IQR 19-25 months). The cumulative HCC incidence of the low, intermediate and high risk group was $0.0,0.6$ and $3.2 \%$ per year, respectively. The patient numbers with a low-risk PAGE-B score $(\leq 9$ points) were applied to calculate cost reduction by PAGE-B adapted HCC screening.

\section{Time requirements of sonographic HCC screening}

The examiner and assistant staff were occupied for a median total exam time of 12.4 min (IQR 9.2-17.2 min) during liver ultrasound. This included a hands-on time of 5.4 min (IQR 4.1-7.8 min) for the examiner. The remaining time span was used for room preparations and documentation of the findings. The total exam time of the liver ultrasound was selected for subsequent work cost calculations during HCC screening. An administrative time of $30 \mathrm{~s}$ were estimated for the out-patient clinic as well as the endoscopy ward, respectively.

In parallel, patients were involved in HCC screening during a median total turnaround time of $45.0 \mathrm{~min}$ (IQR 34.0-59.8 $\mathrm{min}$ ). The median total turnaround time was applied for calculation of external opportunistic costs for sonographic HCC screening.

\section{Full cost calculation of sonographic HCC screening}

Full cost calculation for sonography included costs for instruments, software, technical services, facilities and consumables (Table 2). Average personnel costs expenses for administration $(0.346 € / \mathrm{min})$, medical assistance $(0.418 € / \mathrm{min})$ and physicians $(0.574 € / \mathrm{min})$ were adjusted to the median total exam time and administration time as outlined above.

Full costs calculation for HCC screening eventually resulted in a total of $22.82 € /$ exam (Table 3 ). A capacity utilization of $75 \%$ was applied for the diagnostic sonography unit, as our institution runs two additional work places, used as back up for diagnostic or interventional sonographies. The capacity utilization grade was applied to correct for fixed costs, whereas consumable costs and personnel costs were purely based on exam numbers. A yearly interest rate was applied to account for general price increases as well as personnel expenses. The approximated yearly inflation rates were obtained from the German federal office for statistics survey [12].

\section{Opportunistic expenses for sonographic HCC screening}

Opportunistic costs result from patients lost income and lost productivity during HCC screening. The income calculation is based on the assumption, that $\mathrm{cHB}$ patients are typically fully integrated in the employment market. This particularly holds true for $\mathrm{cHB}$ patients without disease activity and no impairment of liver function, as observed in our cohort (Table 1).

German federal office income statistics were applied and adjusted to the median age of male patients (32.7 years, IQR 31.1-35.2 years) and female patients (49.9 years, IQR 38.9-56.4 years) from the cHB cohort [13]. According to available data (year 2014) an average gross income of $19.13 €$ /hour for men and $17.08 € /$ hour for women was extrapolated. The resulting income loss was $17.5 € /$ exam for male patients and $15.6 € /$ exam for female patients for the year of assessment. Finally, German unemployment rates of $4.1 \%$ for men and $3.3 \%$ for women as well as an annual wage increase of $2 \%$ as published by the German federal agency were taken into account [14]. Unemployed patients were not considered for calculation of lost income. Income of retired patients (age $>65$ years) was assumed to be $15.5 \%$ of working persons income (age 15-64 years), due to paid activities at older ages [15] (Table 4).

Gross domestic product (GDP) per working hour was also considered, as wages do not directly reflect overall productivity. Therefore, the average GDP of 35.56 $€ /$ hour, from the year 2017, was adjusted to the total turnaround time ( $45 \mathrm{~min})$, resulting in a GDP loss of $26.7 € /$ exam $[16,17]$. Unemployed and retired patients were excluded from GDP calculation, as GDP reflects overall average work force productivity (age 15-64 years) of an economic region $[16,17]$.

\section{Cost reduction by PAGE-B score adapted HCC screening}

The annual cost reduction at our institution was calculated on the basis of the full costs for liver sonography and the number of $\mathrm{CHB}$ patients with a low risk PAGE-B score ( $\leq 9$ points) receiving NA treatment. This assessment led to a cost reduction of $2145 €$ for HCC screening during the year 2018 (Table 5). Given that only age is a time dependent variable of the PAGE-B score, whereas gender and thrombocyte count remaining unchanged, we extrapolated the number of annual HCC screens until a PAGE-B score of 10 points was reached. 
Table 1 Characteristics of chronic Hepatitis B patients

\begin{tabular}{|c|c|c|c|}
\hline $\begin{array}{l}\text { Population } \\
\text { Variables } \\
\end{array}$ & $\begin{array}{l}\text { Total } \\
(n=607) \\
\text { Median (IOR) }\end{array}$ & $\begin{array}{l}\text { PAGE-B eligible } \\
(n=227)\end{array}$ & $\begin{array}{l}\text { PAGE-B eligible } \\
\text { \& low risk } \\
(n=94)\end{array}$ \\
\hline Age (years) & $46.7(37.2-57.0)$ & $50.8(41.8-59.4)$ & $42.9(33.6-54.0)$ \\
\hline Age $>65$ years & $74(12.2 \%)$ & $34(15.0 \%)$ & $6(6.4 \%)$ \\
\hline Gender (male/female) & $361 / 246(59.5 / 40.5)$ & 143/84 (63.0/37.0) & $27 / 67(28.7 / 71.3)$ \\
\hline HBsAg positive & $607(100)$ & $227(100)$ & $94(100)$ \\
\hline HBsAg (IU/I) & $1665(358-5222)$ & $1714(556-4909)$ & $3700(1199-8527)$ \\
\hline Anti HBc-Ab & $579(95.5)$ & $222(97.8)$ & $91(96.8)$ \\
\hline HBeAg positive & $50(8.3)$ & $29(12.8)$ & $16(17.0)$ \\
\hline Anti HBe-Ab & $517(85.3)$ & $179(78.9)$ & $76(80.9)$ \\
\hline HBV DNA $<20$ U/I & $331(54.6)$ & $197(86.8)$ & $74(78.7)$ \\
\hline \multicolumn{4}{|l|}{ Ethnicity } \\
\hline Caucasian & $519(85.5 \%)$ & $211(92.9 \%)$ & 86 (91.5\%) \\
\hline Asian & $44(7.2)$ & $14(6.2 \%)$ & $7(7.4 \%)$ \\
\hline African & $32(5.3 \%)$ & $2(0.9 \%)$ & $1(1.1 \%)$ \\
\hline not rated & $12(2.0 \%)$ & $0(0.0 \%)$ & $0(0.0 \%)$ \\
\hline \multicolumn{4}{|l|}{ Laboratory variables } \\
\hline $\mathrm{ALT}(\mathrm{U} / \mathrm{I})$ & $29(21-40)$ & $29(23-34)$ & $28(20-28)$ \\
\hline AST (U/l) & $28(24-35)$ & $29(21-41)$ & $27(22-33)$ \\
\hline Total Bilirubin (mg/dl) & $0.45(0.62-0.85)$ & $0.62(0.45-0.92)$ & $0.56(0.40-0.78)$ \\
\hline Albumin (g/l) & $40(38-42)$ & $40(38-42)$ & $30(38-42)$ \\
\hline Quick (\%) & $96(87-104)$ & $96(88-105)$ & $96(90-108)$ \\
\hline Thrombocytes $\left(\times 10^{9} / 1\right)$ & $219(175-262)$ & $229(186-265)$ & 247 (227-286) \\
\hline \multicolumn{4}{|l|}{ Clinical variables } \\
\hline Deceased & $3(0.5)$ & $1(0.4)$ & $0(0.0)$ \\
\hline $\mathrm{HCC}$ & $7(1.2)$ & $1(0.4)$ & $0(0.0)$ \\
\hline Liver stiffness (kPa) & $4.8(4.0-6.5)$ & $4.9(4.1-6.7)$ & $4.5(3.8-6.2)$ \\
\hline Liver stiffness (> $10 \mathrm{kPa}$ ) & $17(2.8)$ & $12(5.3)$ & $2(2.1)$ \\
\hline \multicolumn{4}{|l|}{ Risk Scores } \\
\hline PAGE-B Score & $10(6-14)$ & $10(6-10)$ & $6(4-8)$ \\
\hline$\leq 9$ Points & $252(41.6)$ & $94(41.4)$ & $94(100)$ \\
\hline 10-17 Points & $273(45.0)$ & $100(44.1)$ & - \\
\hline$\geq 18$ Points & $81(13.4)$ & $33(14.5)$ & - \\
\hline \multicolumn{4}{|l|}{ Antiviral Therapy } \\
\hline Entecavir & $110(18.2)$ & $105(46.3)$ & $41(43.6)$ \\
\hline TDF & $118(19.5)$ & $118(52.0)$ & $49(52.1)$ \\
\hline TAF & $4(0.7)$ & $4(1.8)$ & $4(4.3)$ \\
\hline Lamivudine & $14(2.3)$ & - & - \\
\hline Adefovir & $11(1.8)$ & - & - \\
\hline Telbivudine & $1(0.2)$ & - & - \\
\hline Interferon-alpha & $3(0.5)$ & - & - \\
\hline no antiviral treatment & $345(56.9)$ & - & - \\
\hline
\end{tabular}

Patient characteristics with confirmed chronic hepatitis $B(n=607)$. The subgroups of PAGE-B eligible patients $(n=227)$ as well as PAGE-B eligible patients with low HCC risk $(n=94)$ are shown. All patients attended the infectious and liver disease out-patient clinic during the year 2018 . IQR Interquartile range, TDF Tenofovir disoproxil fumarate, TAF Tenofovir alafenamide fumarate 
Table 2 Expenses for the sonography unit

\begin{tabular}{lll}
\hline Facility expenses $^{\mathrm{a}}$ & Euro/m ${ }^{2} /$ year & Euro/room ${ }^{\mathrm{a}} /$ year \\
Facility fee & 67.8 & $10,712.4$ \\
Facility services & 62.76 & 9916.08 \\
Energy supply & 4.98 & 786.84 \\
Water supply & 3.68 & 581.44 \\
Consumable expenses & Amount/exam & Euro/exam \\
Paper cover (n) & 1 & 0.08 \\
Paper towels (n) & 6 & 0.08 \\
Desinfection towel (n) & 1 & 0.05 \\
Sonography gel (g) & $4.9 \mathrm{~g}$ & 0.01 \\
Disposable gloves (n) & $(2)$ & 0.07 \\
Print out (Paper/Toner) (n) & 1 & 0.01 \\
Fixed costs & Amount & Cost (Euro) \\
Computer & 1 & 625.94 \\
Printer hardware & 1 & 143.72 \\
Administration workplace license & $1 /$ year & 1904 \\
Viewpoint workplace license & $1 /$ year & 500 \\
\hline
\end{tabular}

${ }^{a}$ Facility expenses were calculated on basis of the sonography room $\left(15.8 \mathrm{~m}^{2}\right)$. Consumable spendings and IT-support costs were derived from the institutional listed prices. ${ }^{b}$ Including operating system software license

Based on these assumptions a median of $n=12$ (IQR 612) postponed sonographies per person was calculated for our cohort, which makes a total of $n=1410$ sonography screenings in total. A more restrictive calculation for a maximum 5-year follow-up, identified a total of $n=436$ postponed HCC screenings. This resulted in a total full cost reduction of $10,488 €$ for a 5 -year period (Table 5).

Nationwide cost reduction by PAGE-B adapted HCC screening was derived from population-based source data (additional Table 2), reporting $\mathrm{cHB}$ prevalence rates of $0.3 \%$ up to $0.7 \%$ in Germany [18-21]. The number of eligible patients was further adjusted by the rate (8593\%) of Caucasian HBsAg positive patients (Table 1) [22]. Treatment criteria according to management guidelines were considered, as only patients under second-generation NA therapy are eligible for PAGE-B scoring [3]. Due to the limited population-based data on $\mathrm{cHB}$ and liver fibrosis in Germany, only a relevant HBV viral load (> $2000 \mathrm{IU} / \mathrm{ml})$ in 14.7 to $31.4 \%$ and an elevated ALT activity in 43.8 to $59.4 \%$ were considered among HBsAg-positive patients [19, 22, 23]. These data resulted in an estimated number of 13,169 up to 97,393 HBsAg-positive Caucasian patients with antiviral therapy indication in Germany [19, 22, 23]. Corresponding annual NA therapy costs for a total of 7,475,132 treatment days resulted in coherent patient numbers $(n=20,480)$ in Germany [24]. Eventually the proportion of a low risk PAGE-B score ( $\leq 9$ points) was derived from two trials and from our $\mathrm{CHB}$ population, resulting in $24.7 \%$ [8],
38.6\% [9] and 44.1\% (Table 1), respectively. This range eventually results in a total number of 3253-42,950 NA treated cHB patients with low HCC risk in Germany.

The estimated population-based costs reduction for HCC screening in Germany was 154,116 - 2,034,951€ per year, based on the full costs for liver sonography and the loss of GDP (Table 6). Extrapolation for a 5-year period, which covers an average of 4.63 postponed sonographies per patient, resulted in a cost reduction (incl. GDP) of $731,557 €$ up to $9,421,823 €$ for the German population.

Given that our full cost calculation may differ from other institutions, we included health insurance reimbursement for an abdominal ultrasound (15.91€/exam according to EBM 33042) to extrapolate HCC screening expenses in Germany [25]. This approach identified a cost reduction (incl. GDP) of $131,704 €$ up to $1,739,025$ $€$ per year and $609,789 €$ up to $8,051,686 €$ during a 5year period, respectively (additional Table 2).

Factors determining the number of PAGE-B eligible patients in Germany were included into a sensitivity analysis. cHB patient race was also considered, as nonCaucasian patients show a higher overall HCC risk during hepatitis B [26, 27] (Fig. 1a). A comprehensive list of input variables is provided in additional Table 3. Individual sensitivity analyses for HCC screening costs are provided, based on full costs, reimbursements and opportunistic cost due to lost income or lost GDP, respectively (Fig. 1b-e).

\section{Expenses for omitted HCC diagnosis following PAGE B tailored screening}

Postponing HCC screening in the PAGE-B group with low HCC risk could cause costs and a residual health burden by omitted HCC diagnosis. Therefore, indirect costs resulting from missed early $\mathrm{HCC}$ diagnosis were extrapolated from the life benefit of HCC screening. Compared to unscreened patients the median survival benefit of HCC screening reaches 5-12 months in cirrhotic patients $[28,29]$. The gained life period was subsequently corrected by an average off-work period (94 days per year) caused by the debilitating consequences of malignant diseases [30,31]. Based on this calculation the median effective time benefit of HCC screening was 473 working hours or 1135 working hours, due to a low (screening interval $>6$ months) or a strict screening adherence (screening interval $\leq 6$ months), respectively (additional Table 4). Productivity during these time periods eventually resulted in an income benefit of $10,730 €$ / 25,753€ (low/strict screening adherence) and a GDP benefit of 16,843/ $40,423 €$ (low/strict screening adherence) for each HCC diagnosed via screening. 
Table 3 Full cost calculation for a single liver sonography (75\% capacity utilization)

\begin{tabular}{|c|c|c|c|c|c|c|}
\hline & \multicolumn{5}{|c|}{ Costs per exam } & \multirow[t]{2}{*}{ Factor } \\
\hline & 2018 & 2019 & 2020 & 2021 & 2022 & \\
\hline \multicolumn{7}{|l|}{ Consumables costs } \\
\hline Paper cover & 0.080 & 0.081 & 0.082 & 0.082 & 0.083 & 1.01 \\
\hline Paper towels & 0.080 & 0.081 & 0.082 & 0.082 & 0.083 & 1.01 \\
\hline Desinfection towel & 0.050 & 0.051 & 0.051 & 0.052 & 0.052 & 1.01 \\
\hline Sonography gel & 0.010 & 0.010 & 0.010 & 0.010 & 0.010 & 1.01 \\
\hline Disposable gloves & 0.070 & 0.071 & 0.071 & 0.072 & 0.073 & 1.01 \\
\hline Print out (Paper/Toner) & 0.010 & 0.010 & 0.010 & 0.010 & 0.010 & 1.01 \\
\hline \multicolumn{7}{|l|}{ Fixed costs } \\
\hline Sonography instrument & 3.755 & 3.755 & 3.755 & 3.755 & 3.755 & 1.00 \\
\hline Instrument Service & 0.747 & 0.747 & 0.747 & 0.747 & 0.747 & 1.00 \\
\hline Computer hardware & 0.134 & 0.000 & 0.000 & 0.000 & 0.000 & 1.00 \\
\hline Printer hardware & 0.031 & 0.000 & 0.000 & 0.000 & 0.000 & 1.00 \\
\hline SAP workplace license & 0.406 & 0.406 & 0.406 & 0.406 & 0.406 & 1.00 \\
\hline Viewpoint workplace license & 0.107 & 0.107 & 0.107 & 0.107 & 0.107 & 1.00 \\
\hline Facility fee & 2.285 & 2.308 & 2.331 & 2.355 & 2.378 & 1.01 \\
\hline Facility services & 2.115 & 2.137 & 2.158 & 2.180 & 2.201 & 1.01 \\
\hline Energy supply & 0.168 & 0.171 & 0.175 & 0.178 & 0.182 & 1.02 \\
\hline Water supply & 0.124 & 0.125 & 0.127 & 0.128 & 0.129 & 1.01 \\
\hline \multicolumn{7}{|l|}{ Personnel costs } \\
\hline Administration (out-patient clinic) & 0.209 & 0.213 & 0.218 & 0.222 & 0.226 & 1.02 \\
\hline Administration (endoscopy ward) & 0.137 & 0.140 & 0.142 & 0.145 & 0.148 & 1.02 \\
\hline Procedure (medical staff) & 7.116 & 7.258 & 7.404 & 7.552 & 7.703 & 1.02 \\
\hline Procedure (assistent staff) & 5.187 & 5.291 & 5.397 & 5.505 & 5.615 & 1.02 \\
\hline Total costs & 22.820 & 22.961 & 23.271 & 23.587 & 23.908 & \\
\hline
\end{tabular}

Full cost pricing of diagnostic liver sonographies was based on a total median exam time of 12.4 min as identified for liver sonography. The full costs were calculated on basis of $n=6250$ sonographies per year at a capacity utilization of $75 \%$. Factor, inflation rate

A break-even cost calculation between PAGE-B tailored HCC screening and omitted HCC diagnosis was performed. We applied a screening interval $>6$ months in non-cirrhotic $\mathrm{cHB}$ patients and included a pooled sensitivity of $86 \%$ (95\%CI $75-95 \%)$ for sonographic detection of any stage HCC as well as a sensitivity of $42 \%$ (95\% CI 27-58\%) for early HCC detection to adjust screenings costs, accordingly [32]. Economic break-even is achieved by PAGE-B tailored screening, if annual HCC incidence does not exceed $0.28 \%$ (100\% sensitivity), $0.33 \%$ ( $85 \%$ sensitivity) and $0.67 \%$ ( $42 \%$ sensitivity) in the low HCC risk group. The corresponding GDP break-even calculation identified a maximum annual HCC incidence of $0.12 \%$ (100\% sensitivity), $0.14 \%$ ( $85 \%$ sensitivity) and $0.28 \%$ (42\% sensitivity) in the low HCC risk group, respectively. Additional institutional cost by omitted HCC diagnosis were not expected, as screening does not prevent HCC occurrence and early diagnosis of localized HCC is associated with higher health care costs [31].

\section{Discussion}

The PAGE-B score was successfully introduced to tailor HCC surveillance in our $\mathrm{cHB}$ patient cohort. This included cautious selection of $\mathrm{CHB}$ monoinfected patients receiving NA therapy for one year, who are eligible to apply the PAGE-B score. The low risk subgroup defined by the PAGE-B score $\leq 9$ points hereby showed no residual HCC risk, as previously identified by different clinical trials $[8,9]$. Following this approach at our institution the PAGE-B score reduced annual sonography unit costs by $15.51 \%$ for HCC screening of $\mathrm{cHB}$ patients. This equals a cost reduction of $1.91 \%$ for our annual sonography expenses. In comparison, population-based estimates suggested to postpone HCC screening in $1.35 \%$ up to $7.65 \%$ of $\mathrm{cHB}$ patients in Germany. Given that our referral center for liver diseases reached a high NA therapy uptake of $97 \%(n=258 / 266)$ in cHB patients, the general rate of PAGE-B eligible $\mathrm{cHB}$ patients receiving NA treatment could be comparably lower. Particularly, as European and American trials have reported 
Table 4 Opportunistic wage expenses by patient involvement

\begin{tabular}{|c|c|c|c|c|c|}
\hline \multicolumn{6}{|c|}{ PAGE-B eligible cHB cohort (PAGE-B score $\leq 9$ points) } \\
\hline & 2018 & 2019 & 2020 & 2021 & 2022 \\
\hline Patients (n) & 94 & 91 & 87 & 83 & 81 \\
\hline Male patients (n) & 27 & 27 & 25 & 25 & 23 \\
\hline Employed male patients ( $n$ ) & 26 & 26 & 24 & 24 & 22 \\
\hline Male patients, age < 65 years ( $n$ ) & 26 & 26 & 24 & 24 & 22 \\
\hline Male patients, age $>65$ years $(n)^{a}$ & 0 & 0 & 0 & 0 & 0 \\
\hline Average gross income / hour & 19.1 & 19.5 & 19.9 & 20.3 & 20.7 \\
\hline Average gross income / minute & 0.32 & 0.32 & 0.33 & 0.34 & 0.34 \\
\hline including ancillary labor costs/ minute & 0.39 & 0.40 & 0.41 & 0.41 & 0.42 \\
\hline Opportunistic wage expenses / exam & 17.5 & 17.9 & 18.3 & 18.6 & 19.0 \\
\hline Total costs (male patients) & 454.0 & 463.5 & 437.2 & 446.5 & 419.0 \\
\hline Female patients $(n)$ & 67 & 65 & 62 & 59 & 58 \\
\hline Employed female patients ( $n$ ) & 65 & 63 & 60 & 57 & 56 \\
\hline Female patients, age < 65 years $(n)$ & 61 & 59 & 56 & 54 & 52 \\
\hline Average gross income / hour & 17.1 & 17.4 & 17.8 & 18.1 & 18.5 \\
\hline Average gross income / minute & 0.29 & 0.29 & 0.30 & 0.30 & 0.31 \\
\hline including ancillary labor costs/ minute & 0.35 & 0.36 & 0.36 & 0.37 & 0.38 \\
\hline Opportunistic wage expenses / exam & 15.7 & 16.0 & 16.3 & 16.7 & 17.0 \\
\hline Total costs (female patients, age $<65$ years) & 953.0 & 941.1 & 917.7 & 893.0 & 888.9 \\
\hline Female patients, age $>65$ years $(n)$ & 4 & 4 & 4 & 3 & 3 \\
\hline Average gross income / hour & 2.6 & 2.7 & 2.7 & 2.8 & 2.9 \\
\hline Average gross income / minute & 0.04 & 0.04 & 0.05 & 0.05 & 0.05 \\
\hline including ancillary labor costs/ minute & 0.05 & 0.05 & 0.06 & 0.06 & 0.06 \\
\hline Opportunistic wage expenses / exam & 2.4 & 2.5 & 2.5 & 2.6 & 2.6 \\
\hline Total costs (female patients, age > 65 years) & 9.4 & 9.3 & 9.0 & 8.8 & 8.8 \\
\hline Total costs (all female patients) & 962.4 & 950.4 & 926.8 & 901.8 & 897.7 \\
\hline Total costs & 1416.4 & 1413.8 & 1363.9 & 1348.3 & 1316.7 \\
\hline
\end{tabular}

Opportunistic, age and gender adjusted costs of sonographic HCC screening during a median turnaround time of 45 min in PAGE-B eligible cHB patients with low HCC risk. All patients attended the infectious and liver disease out-patient clinic during the year 2018 . Unemployment rates of $4.1 \%$ for men and $3.3 \%$ for women were considered as published by the German federal agency [14]. An annual income increase of $2 \%$ was applied. Unemployed patients were excluded from income calculations. Income of retired patients (age $>65$ years) was assumed to be $15.5 \%$ of a working persons income (age $15-64$ years) [15]. ${ }^{a}$ Male patients age $>60$ years are excluded by PAGE-B score $\leq 9$ points

an average NA treatment uptake of only $41 \%$ in $\mathrm{cHB}$ patients with therapy indication [33].

The presented full cost calculation identified lower expenses for diagnostic sonography compared to published costs of 31.43-51.47 € per exam [34]. These differences result from a shorter exam time $(12.4 \mathrm{~min})$ quantified at our institution, compared to the exam time $(\sim 20 \mathrm{~min})$ assumed by the other authors [35, 36]. A time-related effect particularly holds true, as full costs for diagnostic sonography adjusted to $20 \mathrm{~min}$ were $37.18 €$ per exam, which was in line with a recent German cost calculation [34]. However, the exam time of previous studies was either derived from a limited number of sonographies $(n=30)$ [36] or was assessed by a practitioner questionnaire, which did not include any standardized time acquisition [35]. Therefore, robust data are provided by the presented approach, which employed a reliable time tracking system during the project, avoiding any time lag between the monitored activity and documentation. More so, the study focused on HCC screening in the ambulatory setting, which potentially reduced the average exam time, as shorter exam times for out-patients (18.9 $\mathrm{min}$ ) compared to hospitalized patients $(21.7 \mathrm{~min})$ were observed during sonography [35].

The presented consumable costs were based on a published cost point composition, which covers all aspects of sonography screening [34]. Our assumptions did not include variable instrument expenses between $50,000 €$ and $125,000 €$, depending on the configuration of ultrasonography unit. Instrument expenses may therefore alter costs for a single liver ultrasound to $21.22 €(-$ $7.02 \%)$ and $24.45 €(+7.15 \%)$. Marginal differences 
Table 5 Annual full cost reduction for PAGE-B tailored liver sonography

\begin{tabular}{|c|c|c|c|c|c|c|}
\hline & \multicolumn{5}{|c|}{$\begin{array}{l}\text { Total costs reduction for cHB patients } \\
\text { (PAGE-B score } \leq 9 \text { points) }\end{array}$} & \multirow[t]{2}{*}{ Factor } \\
\hline & 2018 & 2019 & 2020 & 2021 & 2022 & \\
\hline Patients (n) & 94 & 91 & 87 & 83 & 81 & \\
\hline \multicolumn{7}{|l|}{ Consumables costs } \\
\hline Paper cover & 7.52 & 7.37 & 7.13 & 6.81 & 6.72 & 1.01 \\
\hline Paper towels & 7.52 & 7.37 & 7.13 & 6.81 & 6.72 & 1.01 \\
\hline Desinfection towel & 4.70 & 4.64 & 4.44 & 4.32 & 4.21 & 1.01 \\
\hline Sonography gel & 0.94 & 0.91 & 0.87 & 0.83 & 0.81 & 1.01 \\
\hline Disposable gloves & 6.58 & 6.46 & 6.18 & 5.98 & 5.91 & 1.01 \\
\hline Print out (Paper/Toner) & 0.94 & 0.91 & 0.87 & 0.83 & 0.81 & 1.01 \\
\hline \multicolumn{7}{|l|}{ Fixed costs } \\
\hline Sonography instrument & 352.94 & 352.94 & 352.94 & 352.94 & 352.94 & 1.00 \\
\hline Instrument Service & 70.19 & 70.19 & 70.19 & 70.19 & 70.19 & 1.00 \\
\hline Computer hardware & 12.55 & 0.00 & 0.00 & 0.00 & 0.00 & 1.00 \\
\hline Printer hardware & 2.88 & 0.00 & 0.00 & 0.00 & 0.00 & 1.00 \\
\hline SAP workplace license & 38.18 & 38.18 & 38.18 & 38.18 & 38.18 & 1.00 \\
\hline Viewpoint workplace license & 10.03 & 10.03 & 10.03 & 10.03 & 10.03 & 1.00 \\
\hline Facility fee & 214.82 & 216.97 & 219.14 & 221.33 & 223.54 & 1.01 \\
\hline Facility services & 198.85 & 200.84 & 202.85 & 204.88 & 206.93 & 1.01 \\
\hline Energy supply & 15.78 & 16.09 & 16.42 & 16.75 & 17.08 & 1.02 \\
\hline Water supply & 11.66 & 11.78 & 11.89 & 12.01 & 12.13 & 1.01 \\
\hline \multicolumn{7}{|l|}{ Personnel costs } \\
\hline \multicolumn{7}{|l|}{ Administration } \\
\hline out-patient clinic & 19.65 & 19.38 & 18.97 & 18.43 & 18.31 & 1.02 \\
\hline endoscopy ward & 12.88 & 12.74 & 12.35 & 12.04 & 11.99 & 1.02 \\
\hline \multicolumn{7}{|l|}{ Diagnostic procedure } \\
\hline medical staff & 668.90 & 660.48 & 644.15 & 626.82 & 623.94 & 1.02 \\
\hline assistant staff & 487.58 & 481.48 & 469.54 & 456.92 & 454.82 & 1.02 \\
\hline Total costs & 2145.08 & 2118.76 & 2093.26 & 2066.05 & 2065.26 & \\
\hline
\end{tabular}

Annual full cost pricing was based on a total median exam time of 12.4 min as identified for liver sonography a capacity utilization of $75 \%$. The full costs were calculated on the basis of patients, who did not require sonography HCC screening according to a low PAGE-B risk score of $\leq 9$ points. Factor, inflation rate

compared to published full cost calculations were also observed for the personnel costs, as medical training at our institution has some effect on personnel related expenses. Despite these observational limitations we provide a precise cost assessment, which is in line with previous cost calculations and could be generalized for the HCC screening in Germany [34].

The total population-based costs for sonographic HCC screening were based on the full costs for liver sonography and productivity loss in patients. Estimates of lost productivity (GDP) (26.7 €/exam) or lost earnings (15.6$17.5 € /$ exam) hereby dependent on the cross section of the analyzed population [37, 38]. Current German population surveys and census were applied for this project, which do not entirely represent the composition of $\mathrm{cHB}$ patients $[13,39]$. Hence, data were adjusted for age and gender, as younger female patients assigned to low PAGE-B risk group have a lower income and productivity compared to the average population $[13,16]$. Due to limited data, the rate of foreign $\mathrm{cHB}$ patients for example and their specific human capital could not be considered. A microcensus showed that among households with a low income $(<500 € /$ month) the rate of persons with migration background is $66.2 \%$ for example [40]. Given that an immigration status was present in 35.6 up to $60 \%$ of HBsAg-positive persons, this has some impact on the estimated human income loss $[19,22]$.

Analysis of reimbursements for HCC screening seems more reliable for nationwide cost exploration, as reimbursements are not affected by local cost factors. Estimated savings of reimbursement (incl. GDP) by PAGE-B tailored HCC screening were $15.5 \%$ lower compared to 
Table 6 Screening costs for hepatitis B patients (PAGE-B $\leq 9$ pts.) in Germany

\begin{tabular}{|c|c|c|c|c|c|}
\hline \multicolumn{6}{|c|}{ PAGE-B eligible cHB cohort (PAGE-B score $\leq 9$ points) } \\
\hline & $\mathbf{N}_{\min }$ & $\mathrm{N}_{\max }$ & Costs/Exam & Cost $_{\min }$ & Cost $_{\max }$ \\
\hline Sonography full costs (Euro) & 3253 & 42,950 & 22,8 & 74,164 & 979,262 \\
\hline Opportunistic wage costs (Euro) & $N_{\min }$ & $N_{\max }$ & Costs/Exam & Cost $_{\min }$ & Cost $_{\max }$ \\
\hline Male patients (n) & 934 & 12,327 & - & - & - \\
\hline Employed male patients ( $\mathrm{n}$ ) & 895 & 11,821 & - & - & - \\
\hline Employed male patients, age $<65$ years $(n)$ & 895 & 11,821 & 17,50 & 15,667 & 206,872 \\
\hline Female patients $(n)$ & 2319 & 30,623 & - & - & - \\
\hline Employed female patients (n) & 2243 & 29,613 & - & - & - \\
\hline Employed female patients, age $<65$ years $(n)$ & 2099 & 27,718 & 15,70 & 32,957 & 435,167 \\
\hline Employed female patients, age $>65$ years $(n)$ & 134 & 1774 & 2,40 & 322 & 4257 \\
\hline Total wage costs & - & - & - & 48,947 & 646,297 \\
\hline Sonography costs incl. Opportunistic wage loss & - & - & - & 123,111 & $1,625,559$ \\
\hline Opportunistic GDP loss (Euro) & $\mathrm{N}_{\min }$ & $\mathrm{N}_{\max }$ & Costs/Exam & Cost $_{\min }$ & Cost $_{\max }$ \\
\hline Employed male patients, age < 65 years ( $n$ ) & 895 & 11,821 & 26,70 & 23,904 & 315,628 \\
\hline Employed female patients, age $<65$ years $(n)$ & 2099 & 27,718 & 26,70 & 56,048 & 740,061 \\
\hline Total GDP loss & & & & 79,952 & $1,055,689$ \\
\hline Sonography costs incl. GDP loss & - & - & - & 154,116 & $2,034,951$ \\
\hline
\end{tabular}

Full cost pricing for liver sonography was based on the median total exam time (12.4 min). Opportunistic costs for diagnostic sonography was based on the median turnaround time $(45 \mathrm{~min})$. The total costs were calculated on basis of the estimated cHB prevalence in Germany with antiviral treatment indication $(n=$ 13,169-97,393), which was adjusted by the rate of patients (24.7-44.1\%) with a PAGE-B score $\leq 9$ points. Wage costs and gross domestic productivity (GDP) were adjusted by the unemployment rates of $4.1 \%$ for men and $3.3 \%$ for women as published by the German federal agency [14]. Unemployed patients were excluded from income and GDP calculations. Income of retired patients (age > 65 years) was assumed to be $15.5 \%$ of a working persons income [15], whereas retired patients were excluded from GDP calculation

savings based on full cost calculation (incl. GDP). The driving factor for this difference was lower reimbursement (15.91 €/exam) compared to full costs (22.8 $€ /$ exam) for sonography screening, which confirms a funding gap for sonography in Germany [34]. We therefore argue that full cost calculation covers the entire utilization of health care resources for HCC screening, which highlights the value of empiric data provided by our study.

Health burden and consequence costs by omitted HCC diagnosis after PAGE-B risk stratification became a concern, as an Asian cohort revealed a cumulative 5year incidence of $0.4 \%$ in the low HCC risk group [27, 41]. Improved HCC prediction by incorporation of liver function (albumin) into a modified PAGE-B score hereby indicated that unrecognized liver cirrhosis could be responsible for this finding [27, 42]. Additional host factors seem accountable, as the PAGE-B score in mainly Caucasian patients did not omit residual HCC incidence in the low risk group [8-10]. We argue that remaining HCC risk following a PAGE-B stratification is intrinsic to the East-Asian population, who generally harbor a higher HCC burden during chronic B infection [26]. Racial disparities of non-cirrhotic HCC patients with African and Asian descent are particularly relevant [43], as the PAGE-B score relies on surrogate markers of liver cirrhosis (e.g. thrombocyte counts).
We therefore conclude that PAGE-B tailored HCC screening should be restricted to $\mathrm{CHB}$ patients without liver cirrhosis to minimize consequence costs by omitted HCC diagnoses. In our cHB cohort this was achieved by an initial ultrasound staging or optional liver elastography, which are part of the recommended primary work up of HBV infected patients [3]. Including ethnicity into extrapolation of PAGE-B eligible patients further reduces residual HCC incidence and largely eliminates consequence costs of omitted HCC diagnosis. In fact, eliminating patients with minimal HCC risk would increase HCC incidence in the remaining population. This in turn will raise screening efficacy, as higher pre-screen probability reduces false positive HCC screening results. For example, patient selection by PAGE-B reveals an annual HCC incidence of 0.6 and $3.4 \%$ in intermediate and high risk group, respectively [8-10]. Based on a Markov model a quality adjusted year (QALY) gained via HCC screening would cost $110,000 \$ / Q A L Y$ in the intermediate risk group and only 93,000\$/QALY in the high risk group [44]. Reallocation of HCC screening, therefore, contributes to additional cost savings including institutional and health care expenses (additional Fig. 2). More importantly, avoiding false positive HCC screening results, will also reduce risks associated with unneeded diagnostic procedures or interventions for the patients. 


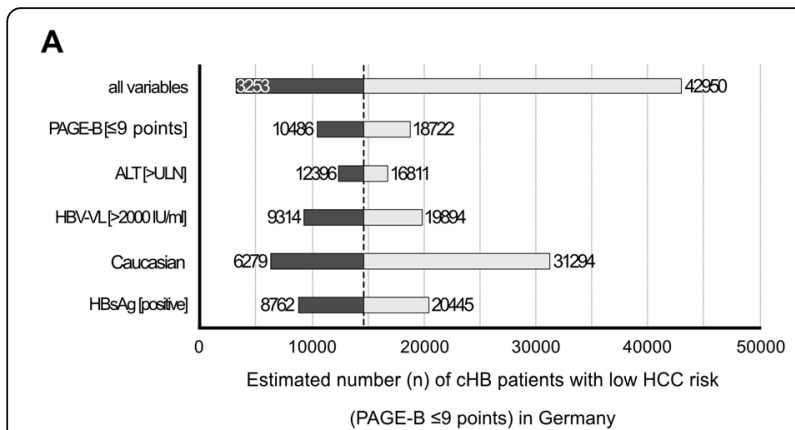

B

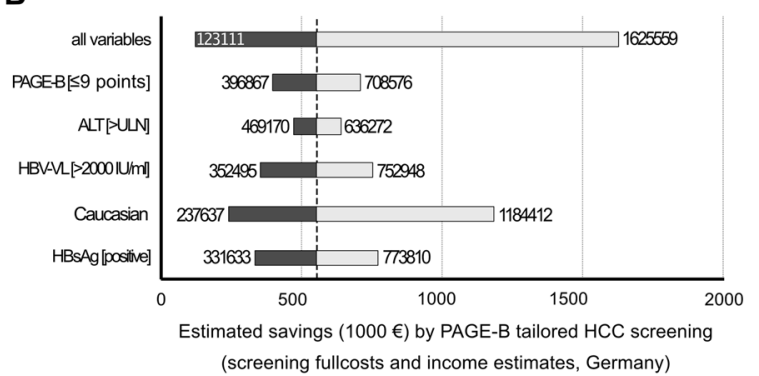

C

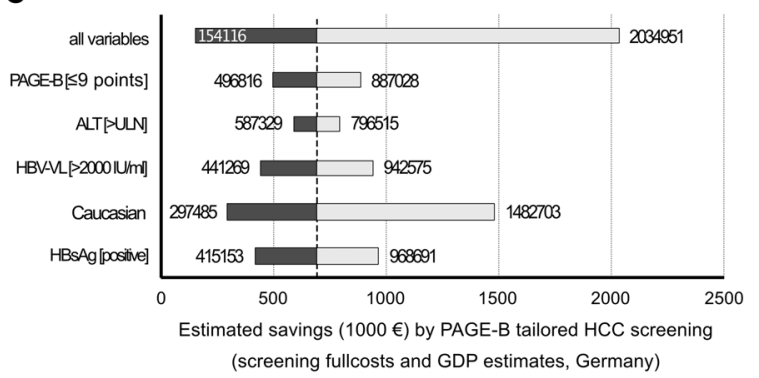

D

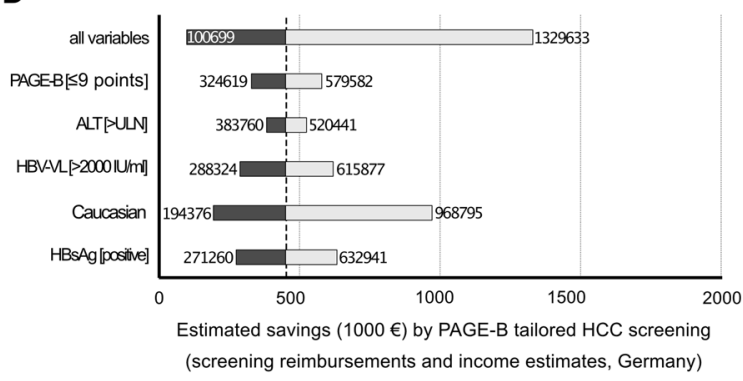

$E$

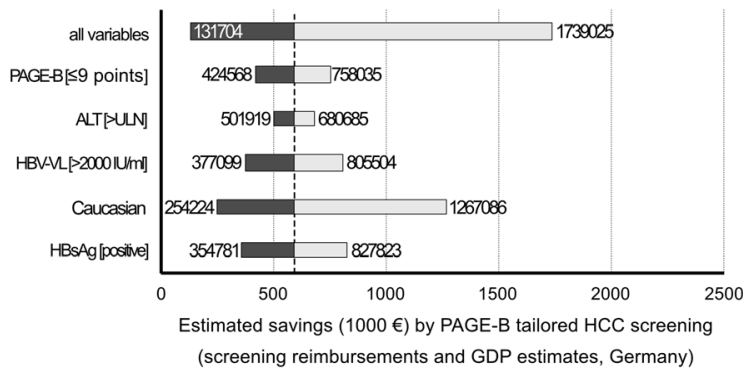

Fig. 1 Sensitivity analysis of screening costs for hepatitis B patients (PAGE-B $\leq 9$ pts.) in Germany
We are aware that our data require adjustment by hepatitis B epidemiology, average income, per capita GDP to apply absolute savings of PAGE-B tailored HCC screening to other countries. Foremost reimbursement for HCC screening depends on regional health politics and recourse allocation. Relative cost reduction derived from our study, however, applies to western European countries, which share similar epidemiological features of hepatitis B [23, 45].

Following our analyses, we conclude that PAGE-B risk score adapted HCC screening of Caucasian cHB patients without liver cirrhosis is efficient and safe to reduce costs. Particularly, automated calculation of the PAGE-B score and its readily available components make it a nearly cost neutral tool to reduce sonography expenses. PAGE-B score-based screening allocation to patients deserving HCC surveillance also protects limited personnel resources. Tailored screening could, therefore, focus on high risk populations, still facing suboptimal uptake of HCC surveillance of 28 to 65\% [46, 47]. Resource sparing risk assessment therefore combines cost reduction as well improvement of healthcare allocation, particularly in context of a relevant funding gap for HCC surveillance.

Tornado blots showing sensitivity analysis of extrapolated screening costs for hepatitis B patients (PAGE$B \leq 9$ pts.) in Germany. Sensitivity analysis of patient numbers (A) eligible for PAGE-B tailored screening was performed. Sensitivity analysis of saved HCC screening full costs, include opportunistic lost income (B) or opportunistic lost GDP (C). Sensitivity analysis of saved HCC screening reimbursements, include opportunistic lost income (D) or opportunistic lost GDP (E).

Input variables and their variances are as follows: $\mathrm{HBsAg}$ positivity rate in the general population $(\mathrm{HBsAg}$, 0.3-0.7\%), rate of Caucasian descent among HBsAg positive patients (85-93\%), hepatitis B replication among HBsAg positive patients (HBV-VL > $2000 \mathrm{IU} / \mathrm{ml}$, 14.7$31.4 \%$ ) and hepatitis among replicative $\mathrm{HBsAg}$ positive patients (ALT >ULN, 43.8-59.4\%). The dashed center line represents costs resulting from average variables according to source data. HBsAg, Hepatitis B surface antigen; ALT, alanine aminotransferase; HBV-VL, hepatitis B virus load; IU, international units; ULN, upper limit of normal.

\section{Abbreviations}

CHB: Chronic hepatitis B; HCC: Hepatocellular carcinoma; NA: Nucleos(t)ide analogues; PAGE-B: Platelet-age-gender-HBV risk score; HBsAg: HBs-antigen; ETV: Entecavir; TDF: Tenofovir disoproxil fumarate; TAF: Tenofovir alafenamid fumarate; n: Number; €: Euro; IQR : Interquartile range; ALT: Alanine aminotransferase; AST: Aspartate aminotransferase; g: Gram; kPa: kiloPascal; U: Units; USD : United States Dollar; I: Liter; ml: Milliliter; min: Minute; GDP: Gross domestic productivity 


\section{Supplementary Information}

The online version contains supplementary material available at https://doi. org/10.1186/s12913-021-06794-6.

Additional file 1: Suppl. Figure 1: Work flow at the out-patient clinic. Suppl. Figure 2: HCC screening costs in relation to HCC incidence. Suppl. Table 1: PAGE-B Score. Suppl. Table 2: Screening reimbursements for hepatitis B patients (PAGE-B $\leq 9$ pts.) in Germany. Suppl. Table 3: Patients with chronic hepatitis $B$ and antiviral therapy indication (Germany). Suppl. Table 4: Productivity benefit per person and HCC diagnosed via screening.

\section{Acknowledgements}

I thank Barbara Eisenmann de Torres for retrieving source data from the hospital information system, Hilde Erbes for providing computed PAGE-B algorithms and Jennifer Ott for reimbursement calculation. I thank my colleagues for source data acquisition during their daily work. I thank all patients for their participation at this project. This publication contains parts of the master thesis of MFS.

\section{Authors' contributions}

MFS: study concept, data analysis, writing the manuscript. CF, WMK: sonographic data acquisition. SK, AW: data management, clinical data acquisition. KLL and PRG: study approval, manuscript revision.

\section{Funding}

Open Access funding enabled and organized by Projekt DEAL.

\section{Availability of data and materials}

The dataset analyzed during the current study is available from the corresponding author on reasonable request.

\section{Declarations}

\section{Ethics approval and consent to participate}

The trial was conducted according to the principles of the Declaration of Helsinki. Approval was provided by the local ethic committee (State Chamber of Medicine, Rhineland-Palatinate, Germany, ethics approval number: 2019-14,206) and by the data safety officer (University Medical Center, Mainz, Germany). A waiver for patient consent was provided by the ethics committee as outlined above.

\section{Consent for publication}

Not applicable.

\section{Competing interests}

The authors declare no financial and non-financial conflict of interest regarding the content of this manuscript.

Received: 16 October 2020 Accepted: 15 July 2021

Published online: 21 August 2021

\section{References}

1. El-Serag HB. Epidemiology of viral hepatitis and hepatocellular carcinoma. Gastroenterology. 2012;142(6):1264-73 e1261.

2. Costentin CE, Layese R, Bourcier V, Cagnot C, Marcellin P, Guyader D, et al. Compliance with hepatocellular carcinoma surveillance guidelines associated with increased Lead-time adjusted survival of patients with compensated viral cirrhosis: a multi-center cohort study. Gastroenterology. 2018;155(2):431-42 e410

3. European Association for the Study of the Liver. Electronic address eee, European Association for the Study of the L: EASL 2017 clinical practice guidelines on the management of hepatitis B virus infection. J Hepatol. 2017;67(2):370-98.

4. Cornberg M, Protzer U, Petersen J, Wedemeyer H, Berg T, Jilg W, et al. Prophylaxis, diagnosis and therapy of hepatitis B virus infection - the German guideline. Z Gastroenterol. 2011;49(7):871-930.

5. Liaw YF, Sung JJ, Chow WC, Farrell G, Lee CZ, Yuen H, et al. Lamivudine for patients with chronic hepatitis B and advanced liver disease. N Engl J Med. 2004;351(15):1521-31.
6. Hosaka T, Suzuki F, Kobayashi M, Seko Y, Kawamura Y, Sezaki H, et al. Longterm entecavir treatment reduces hepatocellular carcinoma incidence in patients with hepatitis B virus infection. Hepatology. 2013;58(1):98-107.

7. Cho JY, Paik YH, Sohn W, Cho HC, Gwak GY, Choi MS, et al. Patients with chronic hepatitis B treated with oral antiviral therapy retain a higher risk for HCC compared with patients with inactive stage disease. Gut. 2014;63(12): 1943-50.

8. Papatheodoridis G, Dalekos G, Sypsa V, Yurdaydin C, Buti M, Goulis J, et al. PAGE-B predicts the risk of developing hepatocellular carcinoma in Caucasians with chronic hepatitis B on 5-year antiviral therapy. J Hepatol. 2016;64(4):800-6.

9. Riveiro-Barciela M, Tabernero D, Calleja JL, Lens S, Manzano ML, Rodriguez FG, et al. Effectiveness and safety of Entecavir or Tenofovir in a Spanish cohort of chronic hepatitis B patients: validation of the page-B score to predict hepatocellular carcinoma. Dig Dis Sci. 2017;62(3):784-93.

10. Brouwer WP, van der Meer AJP, Boonstra A, Plompen EPC, Pas SD, de Knegt $\mathrm{RJ}$, et al. Prediction of long-term clinical outcome in a diverse chronic hepatitis B population: role of the PAGE-B score. J Viral Hepat. 2017;24(11): 1023-31.

11. European Association for the Study of the Liver. Electronic address eee, European Association for the Study of the L: EASL clinical practice guidelines: management of hepatocellular carcinoma. J Hepatol. 2018;69(1): 182-236.

12. Verbraucherpreisindex für Deutschland [https://www.destatis.de/DE/ Themen/Wirtschaft/Konjunkturindikatoren/Basisdaten/vpi001j.html]. Accessed 28 Apr 2021.

13. Genesis-Online database: Income, consumption and living conditions. [https://www.destatis.de]. Accessed 28 Apr 2021.

14. Genesis-Online database: Unemployment [https://www.destatis.de/DE/ Themen/Arbeit/Arbeitsmarkt/Erwerbslosigkeit/_inhalt.html]. Accessed 28 Apr 2021.

15. Johnson RW, Schaner SG. Value of unpaid activities by older americans tops $\$ 160$ billion per year. In: The retirement project. Vol. 2. Washington: The Urban Institute; 2005.

16. Labour productivity per person employed and hour worked [https://ec. europa.eu/eurostat/data/database?node_code=tesem160]. Accessed 28 Apr 2021.

17. Level of GDP per capita and productivity [https://stats.oecd.org/Index.a spx?DataSetCode=PDB_LV]. Accessed 28 Apr 2021.

18. Huetter ML, Fuchs M, Hanle MM, Mason RA, Akinli AS, Imhof A, et al. Prevalence of risk factors for liver disease in a random population sample in southern Germany. Z Gastroenterol. 2014;52(6):558-63.

19. Wolffram I, Petroff D, Batz O, Jedrysiak K, Kramer J, Tenckhoff H, et al. Prevalence of elevated ALT values, HBsAg, and anti-HCV in the primary care setting and evaluation of guideline defined hepatitis risk scenarios. J Hepatol. 2015;62(6):1256-64.

20. Poethko-Muller C, Zimmermann R, Hamouda O, Faber M, Stark K, Ross RS, et al. Epidemiology of hepatitis a, B, and C among adults in Germany: results of the German health interview and examination survey for adults (DEGS1). Bundesgesundheitsbl Gesundheitsforsch Gesundheitsschutz. 2013; 56(5-6):707-15.

21. Thierfelder W, Hellenbrand W, Meisel H, Schreier E, Dortschy R. Prevalence of markers for hepatitis a, B and C in the German population. Results of the German National Health Interview and examination survey 1998. Eur J Epidemiol. 2001;17(5):429-35.

22. Fischer C, Mauss S, Zehnter E, Bokemeyer B, Heyne R, Huppe D. Epidemiology and clinical characteristics of patients with chronic hepatitis B (CHB) in Germany - results of a nationwide cross-sectional study. Z Gastroenterol. 2012;50(1):22-9.

23. Tan M, Bhadoria AS, Cui F, Tan A, Van Holten J, Easterbrook P, et al. Estimating the proportion of people with chronic hepatitis B virus infection eligible for hepatitis B antiviral treatment worldwide: a systematic review and meta-analysis. Lancet Gastroenterol Hepatol. 2021;6(2):106-19.

24. Nutzenbewertungsverfahren zum Wirkstoff Tenofoviralafenamid [https:// www.g-ba.de/bewertungsverfahren/nutzenbewertung/282/]. Accessed 28 Apr 2021.

25. Einheitlicher Bewertungsmaßstab (EBM) [https:/www.kbv.de/html/ebm.php]. Accessed 28 Apr 2021.

26. Raffetti E, Fattovich $G$, Donato F. Incidence of hepatocellular carcinoma in untreated subjects with chronic hepatitis B: a systematic review and metaanalysis. Liver Int. 2016;36(9):1239-51. 
27. Yip TC, Wong GL, Wong WW, Tse YK, Liang LY, Hui WW, et al. Reassessing the accuracy of PAGE-B-related scores to predict hepatocellular carcinoma development in patients with chronic hepatitis B. J Hepatol. 2020;72(5):847-54.

28. Zhang BH, Yang BH, Tang ZY. Randomized controlled trial of screening for hepatocellular carcinoma. J Cancer Res Clin Oncol. 2004;130(7):417-22.

29. Choi DT, Kum HC, Park S, Ohsfeldt RL, Shen Y, Parikh ND, et al. Hepatocellular carcinoma screening is associated with increased survival of patients with cirrhosis. Clin Gastroenterol Hepatol. 2019;17(5):976-87 e974.

30. Yabroff KR, Lawrence WF, Clauser S, Davis WW, Brown ML. Burden of illness in cancer survivors: findings from a population-based national sample. J Natl Cancer Inst. 2004;96(17):1322-30.

31. Lang K, Danchenko N, Gondek K, Shah S, Thompson D. The burden of illness associated with hepatocellular carcinoma in the United States. J Hepatol. 2009;50(1):89-99.

32. Tzartzeva K, Obi J, Rich NE, Parikh ND, Marrero JA, Yopp A, et al. Surveillance imaging and alpha fetoprotein for early detection of hepatocellular carcinoma in patients with cirrhosis: a meta-analysis. Gastroenterology. 2018; 154(6):1706-18 e1701

33. Mahajan $\mathrm{V}$, Jin $\mathrm{M}$, Le MH, Nguyen $\mathrm{N}$, Wong CR, Leong J, et al. Tu1672 low rates of antiviral therapy in chronic hepatitis B (CHB) patients and its geographic variation: a systematic review and meta-analysis of 13 studies and 31,342 patients. Gastroenterology. 2016;150(4):S1163-4.

34. Schuler A, Reuss J, Delorme S, Hagendorff A, Giesel F. Costs of clinical ultrasound examinations - an economical cost calculation and analysis. Ultraschall Med. 2010;31(4):379-86.

35. Reuss J, Weiss H, Wanner T, Leser HG. Time requirements of medical and non-medical personnel for ultrasound studies. Ultraschall Med. 1998;19(3): $126-9$.

36. Teichgraber UK, Benter T, Kluhs L, Schroder RJ, Hidajat N, Dorken B, et al. Project graph technique for time management in abdominal ultrasound evaluations. Ultraschall Med. 1999;20(6):236-41.

37. Glied S. Estimating the indirect cost of illness: an assessment of the forgone earnings approach. Am J Public Health. 1996;86(12):1723-8.

38. World development indicators - Global gender gab indicators 2015 [http:// reports.weforum.org/global-gender-gap-report-2015/the-case-for-genderequality].

39. Bundesamt S: Bevölkerung (Zensus), nach Bundesländer, Stichtag, Nationalität, Altersgruppen. 2018.

40. Bundesamt S. Bevölkerung in Privathaushalten 2017 nach Migrationshintergrund - Nettoeinkommen; 2018.

41. Sonneveld MJ, Brouwer WP, de Man RA. Hepatocellular carcinoma risk stratification in HBV cirrhosis: time to turn the page? J Hepatol. 2020;73(3): 728-9.

42. Kim JH, Kim YD, Lee M, Jun BG, Kim TS, Suk KT, et al. Modified PAGE-B score predicts the risk of hepatocellular carcinoma in Asians with chronic hepatitis B on antiviral therapy. J Hepatol. 2018:69(5):1066-73.

43. Chayanupatkul M, Omino R, Mittal S, Kramer JR, Richardson P, Thrift AP, et al. Hepatocellular carcinoma in the absence of cirrhosis in patients with chronic hepatitis B virus infection. J Hepatol. 2017;66(2):355-62.

44. Parikh ND, Singal AG, Hutton DW, Tapper EB. Cost-effectiveness of hepatocellular carcinoma surveillance: an assessment of benefits and harms. Am J Gastroenterol. 2020;115(10):1642-9.

45. Ott JJ, Stevens GA, Groeger J, Wiersma ST. Global epidemiology of hepatitis $B$ virus infection: new estimates of age-specific HBsAg seroprevalence and endemicity. Vaccine. 2012;30(12):2212-9.

46. Davila JA, Weston A, Smalley W, El-Serag HB. Utilization of screening for hepatocellular carcinoma in the United States. J Clin Gastroenterol. 2007; 41(8):777-82.

47. Selvapatt $\mathrm{N}$, House $\mathrm{H}$, Brown A. Hepatocellular carcinoma surveillance: are we utilizing it? J Clin Gastroenterol. 2016;50(1):e8-e12.

\section{Publisher's Note}

Springer Nature remains neutral with regard to jurisdictional claims in published maps and institutional affiliations.

Ready to submit your research? Choose BMC and benefit from:
- fast, convenient online submission
- thorough peer review by experienced researchers in your field
- rapid publication on acceptance
- support for research data, including large and complex data types
- gold Open Access which fosters wider collaboration and increased citations
- maximum visibility for your research: over 100M website views per year
At BMC, research is always in progress.
Learn more biomedcentral.com/submissions

